\title{
Microenvironmentally controlled secondary structure motifs of apolipoprotein A-I derived peptides
}

\author{
Paola Mendoza-Espinosa • Danai Montalvan-Sorrosa • \\ Victor García-González • Abel Moreno • \\ Rolando Castillo · Jaime Mas-Oliva
}

Received: 29 December 2013/Accepted: 2 April 2014/Published online: 20 April 2014

(C) The Author(s) 2014. This article is published with open access at Springerlink.com

\begin{abstract}
The structure of apolipoprotein A-I (apoA-I), the major protein of HDL, has been extensively studied in past years. Nevertheless, its corresponding three-dimensional structure has been difficult to obtain due to the frequent conformational changes observed depending on the microenvironment. Although the function of each helical segment of this protein remains unclear, it has been observed that the apoA-I amino (N) and carboxy-end (C) domains are directly involved in receptor-recognition, processes that determine the diameter for HDL particles. In addition, it has been observed that the high structural plasticity of these segments might be related to several amyloidogenic processes. In this work, we studied a series of peptides derived from the $\mathrm{N}$ - and $\mathrm{C}$-terminal domains representing the most hydrophobic segments of apoA-I. Measurements carried out using circular dichroism in all tested peptides evidenced that the lipid environment promotes the formation of $\alpha$-helical structures, whereas an aqueous environment facilitates a strong tendency to adopt $\beta$-sheet/disordered conformations. Electron microscopy
\end{abstract}

P. Mendoza-Espinosa · V. García-González · J. Mas-Oliva Instituto de Fisiología Celular, Universidad Nacional Autónoma de México, 04510 México D.F, México

D. Montalvan-Sorrosa $\cdot$ R. Castillo

Instituto de Física, Universidad Nacional Autónoma de México, 04510 México D.F, México

\footnotetext{
A. Moreno

Instituto de Química, Universidad Nacional Autónoma de México, 04510 México D.F, México

J. Mas-Oliva $(\bowtie)$

División de Investigación, Facultad de Medicina, Universidad

Nacional Autónoma de México, 04510 México D.F, México

e-mail: jmas@ifc.unam.mx
}

observations showed the formation of amyloid-like structures similar to those found in other well-defined amyloidogenic proteins. Interestingly, when the apoA-I peptides were incubated under conditions that promote stable globular structures, two of the peptides studied were cytotoxic to microglia and mouse macrophage cells. Our findings provide an insight into the physicochemical properties of key segments contained in apoA-I which may be implicated in disorder-to-order transitions that in turn maintain the delicate equilibrium between both, native and abnormal conformations, and therefore control its propensity to become involved in pathological processes.

Keywords Apolipoprotein A-I · Amyloidogenic peptides $\cdot$ Disorder-to-order transitions

\section{Introduction}

Apolipoprotein A-I (apoA-I) is considered the major component of high-density lipoproteins (HDL) and plays a key role in reverse cholesterol transport, a process that removes excess cholesterol from the cell membranes of peripheral tissues and, therefore, works as a protection mechanism against the development of atherosclerosis [1].

Natively unfolded proteins, such as apoA-I [2], have recently garnered significant interest and led to coin the term unfoldome [3]. Disordered domains in natively unfolded proteins have been associated with protein and lipid transport, transcriptional regulation [4], and a large number of diseases including amyloidosis, cancer, diabetes, and neurodegenerative disorders [5]. Nuclear magnetic resonance (NMR) and electron paramagnetic resonance (EPR) have demonstrated that the amino $(\mathrm{N})$ and carboxyend (C) segment of lipid-free apoA-I present variable 
secondary structures and, therefore, considerable plasticity [6-11].

Several HDL models that go from a discoidal to a spherical shape have suggested that the exposed $\mathrm{N}$ - and C-terminal domains of apoA-I interact with lipids [12-15], and shown that the presence of cholesterol and phospholipids determines whether the apoA-I structure is present in an open or closed conformation [6]. The highly hydrophobic C-terminal domain anchors apoA-I to membranes [16], whereas both the $\mathrm{N}$ - and C-terminal domains have been shown to play roles in receptordependent binding and lipid remodeling of discoidal HDL particles. Antibody binding and cross-linking studies have shown that the apoA-I N- and C-terminal domains interact with the scavenger receptor B1 (SRB1), responsible for the transfer of free cholesterol and cholesteryl-esters to the liver [17, 18]. On the other hand, we have recently shown that several $\alpha$-helical peptides derived from the $\mathrm{N}$ and C-terminal domains of apoA-I are able to activate the plasma enzyme lecithin cholesterol acyltransferase (LCAT) [19]. While several $\alpha$-helical structures of apoA-I and their interactions with proteins and lipids have been widely studied, other protein structural features of apoA-I, such as $\beta$-sheets, have not been systematically investigated. From the few studies performed, site-directed spinlabeling electron paramagnetic resonance spectroscopy (SDSL-EPR) has revealed the presence of a short $\beta$ segment at both the $\mathrm{N}$ - and the C-terminal regions of the lipid-free form of apoA-I [7, 20].

Although several of the conformational transitions in apoA-I are prone to be dependent on their microenvironment, little is known related to its capacity to acquire, depending on this microenvironment, a secondary structure susceptible to aggregation, such as globular forms and $\beta$-sheets.

The most hydrophobic and disordered segments of the $\mathrm{N}$ - and $\mathrm{C}$-end regions of apoA-I were identified through in silico analysis performed for the complete apoA-I sequence. The physicochemical analysis included properties such as hydrophobic moment, charge, average hydrophobicity associated to steric zippers, theoretical average velocity of aggregation, and possible patterns including residues promoting membrane interactions, self-assembling and aggregation. According to these data, we studied the structural features of short peptides derived between $\mathrm{N}$ and C-terminal domains of apoA-I. We identified several apoA-I modules that promote self-assembly and aggregation, and found that the positions of specific key aromatic residues may affect lipid binding. Our results shed light on the mechanisms that regulate localized conformational transitions that in turn might affect the way apoA-I interacts with HDL particles.

\section{Materials and methods}

Peptide synthesis and sample preparation

Three peptides were synthesized (purity $>98 \%$ ) based on the sequence and functional information reported: apoA-I [9-24]/D ${ }^{9}$-RVKDLATVYVDVLKD ${ }^{24}$ (abbreviated in the present study as $\left.\mathrm{DRV}^{(9-24)}\right)$, apoA-I[45-63]/K $\mathrm{K}^{45}$ LLDNWDSVTSTFSKLREQ $^{63}$ (abbreviated in the present study as $\mathrm{KLL}^{(45-63)}$ ), and apoA-I[221-239]/ $\mathrm{V}^{221}$-LES FKVSFLSALEEYTKK ${ }^{239}$ (abbreviated in the present study as VLES ${ }^{(221-239)}$ ) (GenScript Corporation Piscataway, NJ). Lyophilized peptides were dissolved at $1 \mathrm{mg} / \mathrm{mL}$ and diluted to a final concentration of $200 \mu \mathrm{g} / \mathrm{mL}$ in ultrapure water $(18.2 \mathrm{M} \Omega \cdot \mathrm{cm}, \mathrm{pH} 6.8)$, in the presence of $20 \mathrm{mM}$ 1-lauroyl-2-hydroxy-sn-glycero-3-phosphocholine (Lyso-C ${ }_{12}$ PC, CAS RN: 20559-18-6) or $40 \%$ 2,2,2-trifluoroethanol (TFE, CAS RN: 75-89-8). Protein concentrations were determined measuring absorbance at $280 \mathrm{~nm}$.

\section{In silico analysis}

The primary structure of apoA-I was placed into multiple algorithms to predict disorder-susceptible regions, hydrophobic clusters and aggregation-prone regions. The PONDR-FIT algorithm, a meta-predictor that joins the results of six programs (PONDR-VLXT, PONDR-VSL2, PONDR-VL3, FoldIndex, IUPred, and TopIDP) and forms an artificial consensus from these results, was used to predict conformational disorder [21]. Hydrophobic segments were predicted using the hydrophobic cluster analysis (HCA) server [22]. Regions prone to form amyloid fibrils and globular structures were predicted using the Zyggregator server [23]. Zyggregator uses an algorithm that considers patterns of hydrophobicity, as well as the polar and aromatic amino acid content of amyloidogenic proteins. The prediction of the aggregation rate was calculated using the equation of Dubay et al. [24], considering several factors that influence aggregation, such as $\mathrm{pH}$, ionic force, the presence of specific amino acid sequences, net charge, and total hydrophobicity.

\section{Circular dichroism spectroscopy}

Far-ultraviolet (UV) circular dichroism (CD) spectra were recorded on an Aviv 62DS spectropolarimeter in a $0.1 \mathrm{~cm}$ quartz cell using an average time of $2.5 \mathrm{~s}$ and a step size of $0.5 \mathrm{~nm}$ over a wavelength range of 190-260 nm. Sample concentration was determined before each $\mathrm{CD}$ measurement and following baseline correction, ellipticity was converted to mean molar ellipticity $\left(\Theta, \operatorname{deg~} \mathrm{cm}^{2} \mathrm{dmol}^{-1}\right)$. Secondary structure content was calculated at $190-260 \mathrm{~nm}$ 
using the circular dichroism neural network (CDNN) based software [25].

Transmission electron microscopy and atomic force microscopy

Samples of peptide solutions in water were collected after $0,24,48,72,96 \mathrm{~h}$ and 120 days of incubation at $4{ }^{\circ} \mathrm{C}$ and observed using transmission electron microscopy (TEM) with a JEM-1200EX11 JEOL microscope $(70 \mathrm{kV})$ and atomic force microscopy (AFM) performed with an AFM Digital Instruments/Veeco. Peptide solutions for TEM were deposited on carbon-coated transmission electron microscopy grids and stained with $2 \%$ uranyl acetate. Aliquots of peptide solutions in water were deposited onto freshly cleaved mica, dried under laminar flow for $5 \mathrm{~min}$, and visualized by AFM. Images were obtained using a Multimode microscope (Digital Instruments/Veeco) and a Nano Scope IIIa (Digital Instruments/Veeco) control system. Images $(5.0 \times 5.0 \mu \mathrm{m})$ were obtained in contact mode at a scan frequency of $2 \mathrm{~Hz}$ using silicon nitride $\left(\mathrm{Si}_{3} \mathrm{~N}_{4}\right)$ AFM tips.

Viability assays and optical microscopy

RAW (mouse macrophage, ATCC CRL-2467) and EOC cells (mouse microglia, ATCC TIB-71) were grown as previously described by us [26]. Macrophage and microglial cells were placed into 96-well plates at a density of $1 \times 10^{4}$ cells/well $(100 \mu \mathrm{L} /$ well $)$ and incubated for $24 \mathrm{~h}$ at $37^{\circ} \mathrm{C}$. Serial dilutions of aged peptide solutions (120 days at $4{ }^{\circ} \mathrm{C}$ ) were prepared in Opti-MEM reduced-serum medium (OptiMEM) without phenol red. Incubations were performed for $20 \mathrm{~h}$, and cell viability estimated by measuring the cellular reduction of MTT (3-(4, 5-dimethylthiazol-2-yl)-2, 5-diphenyltetrazolium bromide) as previously described by us [26]. Cell images were observed by optical microscopy at $40 \times$ magnification, processed and stored as TIF using an Olympus IX71 microscope and the Image-Pro 3DS 6.0 software.

\section{Results}

In silico analysis of apoA-I and apoA-I-derived peptides

Using the PONDR-FIT algorithm, four disorder-prone regions (amino acids 1-13, 112-154, 204-210, 233-243) were identified in apoA-I (Fig. 1a). The disorder propensity graph shows that segments corresponding to peptides $\mathrm{DRV}^{(9-24)}$ and $\operatorname{VLES}^{(221-239)}$ present a higher tendency toward an unstructured conformation than the highly
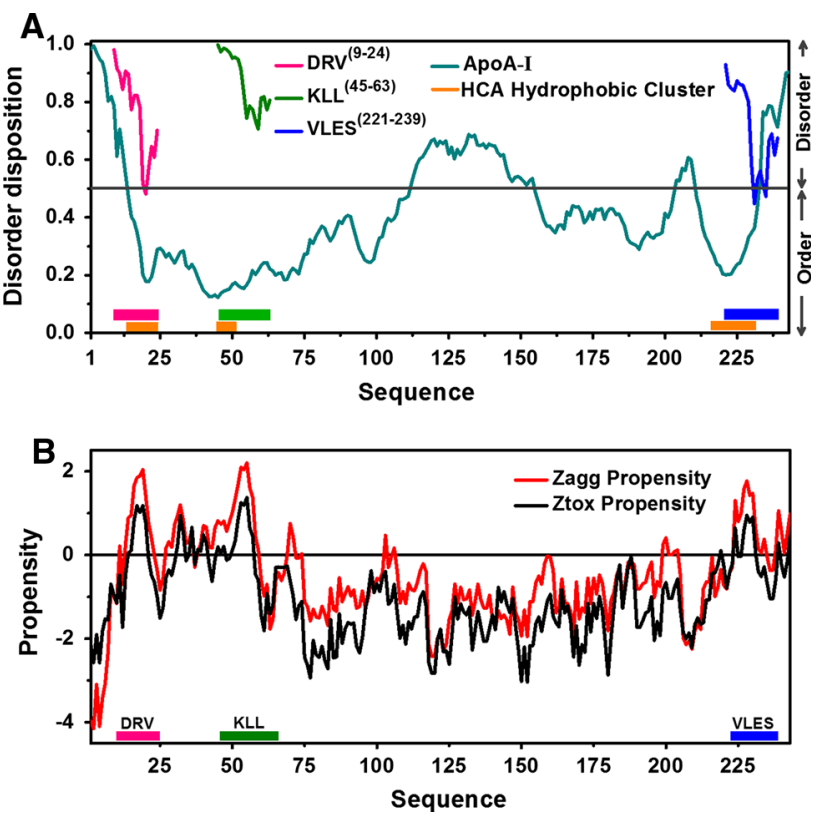

Fig. 1 Disorder and aggregation predictions for apoA-I. a The disorder profiles were created with PONDR-FIT and the hydrophobic clusters predicted using the HCA server. Propensities to disorder for $\mathrm{DRV}^{(9-24)}$ and VLES ${ }^{(221-239)}$ overlapped with the apoA-I disorder profile. b Aggregation profiles of apoA-I were obtained using Zyggregator and prediction of propensity to generate amyloid fibrils and globular structures using Zagg propensity and Ztox propensity respectively

ordered segment KLL ${ }^{(45-63)}$. Nevertheless, when individual peptide sequences rather than the entire protein sequence were analyzed, we observed that peptide $\mathrm{KLL}^{(45-63)}$ presented the highest tendency to become disordered (Fig. 1a). Using the HCA server, three highly hydrophobic segments (amino acids 13-22, 45-49, 216-232) were predicted that precisely correspond to $\mathrm{DRV}^{(9-24)}$, $\mathrm{KLL}^{(45-63)}$, and $\operatorname{VLES}^{(221-239)}$ (Fig. 1a). In addition, Zyggregator identified several native apoA-I sites with the propensity to form amyloid fibrils and globular structures (amino acids 15-20, 50-57, and 224-230). These sites also correspond to peptides $\mathrm{DRV}^{(9-24)}$, $\mathrm{KLL}^{(45-63)}$, and VLES $^{(221-239)}$ (Fig. 1b). The theoretical prediction for aggregation rates (Zag propensity) indicates that peptide VLES $^{(221-239)}$ could form amyloid-like aggregates faster than the other peptides tested (Table 1).

Circular dichroism

Peptides DRV ${ }^{(9-24)}, \mathrm{KLL}^{(45-63)}$, and VLES ${ }^{(221-239)}$ placed in water were monitored by far-UV $\mathrm{CD}$ at $24 \mathrm{~h}$ intervals (Fig. 2a-c) in the presence of $20 \mathrm{mM}$ Lyso- $\mathrm{C}_{12} \mathrm{PC}$ $(\mathrm{cmc}=0.9 \mathrm{mM})$ or $40 \%$ TFE (Fig. $2 \mathrm{~d}-\mathrm{f})$. The percentages for the different secondary structural modules for these peptides were calculated employing the CDNN 
Table 1 Physicochemical properties of peptides DRV ${ }^{(9-24)}, \operatorname{KLL}^{(45-63)}$, and VLES ${ }^{(221-239)}$

\begin{tabular}{|c|c|c|c|}
\hline Peptide & DRV (9-24) & KLL (45-63) & VLES (221-239) \\
\hline $\begin{array}{l}\text { Amino acid } \\
\text { sequence }^{\mathrm{a}}\end{array}$ & DRVKDLATVYVDVLKD & KLLDNWDSVTSTFSKLREQ & VLESFKVSFLSALEEYTKK \\
\hline Average charge & -1 & 0 & 0 \\
\hline $\begin{array}{l}\text { Average } \\
\text { hydrophobicity } \\
(\mathrm{kcal} / \mathrm{mol})\end{array}$ & -0.116 & -0.151 & 0.118 \\
\hline $\begin{array}{l}\text { Hydrophobic } \\
\text { moment } \mu \mathrm{H} \\
(\mathrm{kcal} / \mathrm{mol})\end{array}$ & 0.490 & 0.280 & 0.390 \\
\hline $\begin{array}{l}\text { Steric zipper } \\
\text { hydrophobicity } \\
\text { (kcal/mol) }\end{array}$ & 0.675 & 0.218 & 0.664 \\
\hline $\begin{array}{l}\text { Zag propensity } \\
\log \mathrm{K}\left(\mathrm{s}^{-1}\right)\end{array}$ & -4.3 & -4.5 & -3.2 \\
\hline $\begin{array}{l}\text { Aromatic }(\mathrm{X}) \text { and } \\
\text { positive polar } \\
(\mathrm{P}) \text { amino acids } \\
\text { position into the } \\
\text { peptide sequence }\end{array}$ & $\cdot P \cdot P \cdots \cdots x \cdots P$ P & $P \cdots \cdot x \cdots \cdots \cdot x \cdot P \cdot P \bullet$ & $\cdots x \mathrm{XP} \bullet \mathrm{x} \cdots \cdots \cdot \mathrm{x} \cdot \mathrm{PP}$ \\
\hline $\begin{array}{l}\text { Globular structure } \\
\text { formation }\end{array}$ & Yes & Yes & Yes \\
\hline Fibril formation & Yes & No & Yes \\
\hline Cytotoxicity & Medium & Poor & High \\
\hline
\end{tabular}

a amino acids: positive (blue), negative (red), polar uncharged (green), aromatic (yellow)

b The steric zipper is underlined

Fig. 2 Far-UV CD spectra of apoA-I derived peptides. a-c Spectra of peptide DRV $(9-24)$, $\mathrm{KLL}^{(45-63)}$, and VLES ${ }^{(221-239)}$ incubated for various times in water. $\mathbf{d}-\mathbf{f}$ CD spectra of peptides DRV ${ }^{(9-24)}, \mathrm{KLL}^{(45-63)}$, and VLES ${ }^{(221-239)}$ incubated for $24 \mathrm{~h}$ in $40 \%$ TFE and $20 \mathrm{mM}$ Lyso- $\mathrm{C}_{12} \mathrm{PC}$
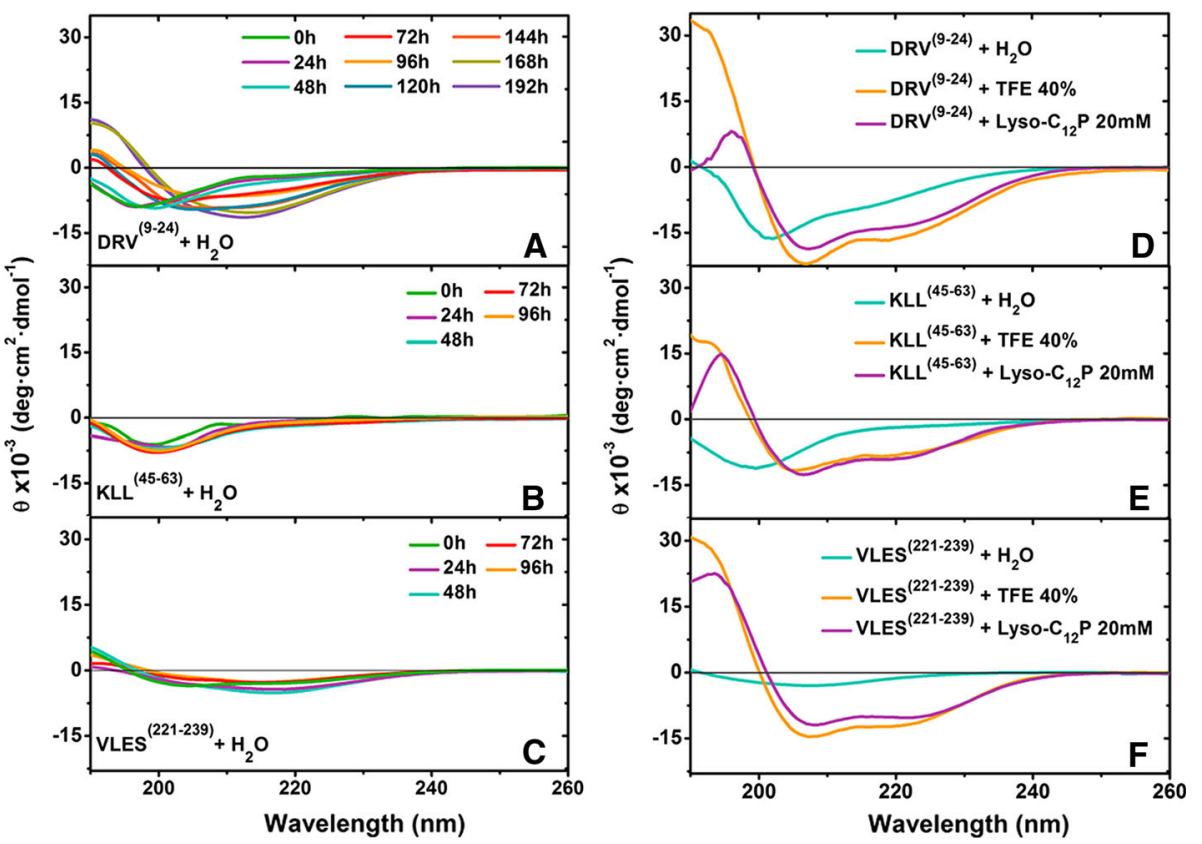

program (Table 2). CD spectra of peptides dissolved in water presented a single minimum around $200 \mathrm{~nm}$ at the 0 timepoint, indicating primarily the presence of disordered structures. The CD spectra deconvolution of $\mathrm{DRV}^{(9-24)}$, $\mathrm{KLL}^{(45-63)}$, and $\operatorname{VLES}^{(221-239)}$ in water displayed a mixture of $\alpha$-helix, $\beta$-sheet, and disordered structures (Table 2). In 
Table 2 Secondary structure content of apoA-I derived peptides in water and in the presence of hydrophobic molecules

\begin{tabular}{|c|c|c|c|c|c|c|c|c|c|c|}
\hline \multirow[t]{3}{*}{ Sample } & \multirow[t]{3}{*}{ Incubation time $(\mathrm{h})$} & \multicolumn{9}{|c|}{ PEPTIDES } \\
\hline & & \multicolumn{3}{|c|}{$\mathrm{DRV}^{(9-24)}$} & \multicolumn{3}{|c|}{$\mathrm{KLL}^{(45-63)}$} & \multicolumn{3}{|c|}{$\operatorname{VLES}^{(221-239)}$} \\
\hline & & $\% \alpha$ & $\% \beta$ & $\% \mathrm{rc}$ & $\% \alpha$ & $\% \beta$ & $\% \mathrm{rc}$ & $\% \alpha$ & $\% \beta$ & $\%$ rc \\
\hline \multirow[t]{9}{*}{$\mathrm{H}_{2} \mathrm{O}$} & 0 & 6.6 & 35.3 & 38.4 & 4.5 & 38.2 & 35.4 & 8.5 & 46.0 & 28.6 \\
\hline & 24 & 7.0 & 34.1 & 38.2 & 5.0 & 36.9 & 35.3 & 10.5 & 47.8 & 27.0 \\
\hline & 48 & 7.3 & 32.3 & 38.4 & 5.1 & 36.4 & 35.2 & 11.1 & 45.2 & 27.7 \\
\hline & 72 & 9.7 & 27.7 & 37.2 & 4.2 & 39.5 & 35.2 & 10.3 & 50.2 & 26.2 \\
\hline & 96 & 11.2 & 26.9 & 36.4 & 4.0 & 41.2 & 35.2 & 10.3 & 46.0 & 27.6 \\
\hline & 120 & 12.7 & 22.0 & 36.8 & & & & & & \\
\hline & 144 & 13.1 & 22.0 & 36.5 & & & & & & \\
\hline & 168 & 16.8 & 19.8 & 34.7 & & & & & & \\
\hline & 192 & 17.6 & 18.4 & 34.5 & & & & & & \\
\hline TFE $40 \%$ & 24 & 47.2 & 0.6 & 26.7 & 26.3 & 19.4 & 28.0 & 39.5 & 2.7 & 25.0 \\
\hline Lyso- $\mathrm{C}_{12} \mathrm{PC} 20 \mathrm{mM}$ & 24 & 26.8 & 3.9 & 46.3 & 24.2 & 13.4 & 28.0 & 34.0 & 5.9 & 26.0 \\
\hline
\end{tabular}

TFE (2,2,2-Trifluoroethanol), Lyso-C ${ }_{12}$ PC (1-lauroyl-2-hydroxy-sn-glycero-3-phosphocholine). $\alpha$ ( $\alpha$-helix), $\beta$ ( $\beta$-sheet), rc (random coil). Secondary structure percentages were estimated using the circular dichroism neural network (CDNN) based software

the presence of Lyso- $\mathrm{C}_{12} \mathrm{PC}$ and TFE, the three peptides showed a clear minimum at 208 and $222 \mathrm{~nm}$ and a maximum at $195 \mathrm{~nm}$, characteristic of an $\alpha$-helix (Fig. 2d-f). Lyso- $\mathrm{C}_{12} \mathrm{PC}$ strongly promoted the recovery of secondary structure from a disordered conformation with all peptides tested. Optimal recoveries occurred with peptide VLES $^{(221-239)}$, whereas the weakest one was shown by peptide $\mathrm{KLL}^{(45-63)}$ (Fig. 2d-f).

Peptide aggregates observed by TEM and AFM

Since an increase in $\beta$-sheet structures suggests the potential formation of amyloid-like fibrils, peptide samples were analyzed by TEM (Fig. 3) and AFM (Fig. 3 insets). This figure shows the different configurations that peptides VLES $^{(221-239)}$ (Fig. 3a-f), DRV ${ }^{(9-24)}$ (Fig. 3g-1) and $\mathrm{KLL}^{(45-63)}$ (Fig. $3 \mathrm{~m}-\mathrm{r}$ ) display over time. Peptide VLES $^{(221-239)}$ at $0 \mathrm{~h}$ revealed protofibrillar structures (arrows, Fig. 3a) that longitudinally grow after $24 \mathrm{~h}$ incubation (Fig. 3b). After 48, 72, and $96 \mathrm{~h}$ incubation (Fig. 3c-e), fibrillar or globular structures did not show any modification. However, after 120 days incubation, peptide VLES $^{(221-239)}$ shows the formation of globular structures that significantly increased in size (Fig. 3f). Peptide $\mathrm{DRV}^{(9-24)}$ displayed a mixture of oligomers and protofibrillar intermediaries at the start of the experiment (Fig. $3 \mathrm{~g}$ ), whereas at $24 \mathrm{~h}$ incubation, we observed long fibrillar structures (Fig. 3h). After 48 and $72 \mathrm{~h}$ incubation, lateral aggregation of fibrils generated wider structures (Fig. 3i,j). At $96 \mathrm{~h}$ incubation, thick bundles of fibrillar structures were found with no additional changes in size seen after 120 days incubation (Fig. 3k,1). In contrast, no fibrillar aggregates were seen during the incubation of $\mathrm{KLL}^{(45-63)}$ peptide over time (Fig. 3m-r).

MTT cell viability assay and optical microscopy

As previously reported by us employing the $\beta$-amyloid peptide, cytotoxic effects of aggregates formed by $\mathrm{DRV}^{(9-24)}, \mathrm{KLL}^{(45-63)}$ and VLES ${ }^{(221-239)}$ were evaluated on macrophage and microglial cells [27], following the reduction of MTT as an indirect indicator of cellular oxidative stress [28]. DRV ${ }^{(9-24)}, \mathrm{KLL}^{(45-63)}$ and VLES ${ }^{(221-239)}$ peptides were incubated for 120 days prior to viability testing. When macrophages were exposed to increasing concentrations of the three tested peptides, cell viability was only slightly decreased in the case of VLES ${ }^{(221-239)}$, with no dependence on peptide concentration (Fig. 4A). For the viability experiment performed with microglial cells, the peptide concentration range was expanded to $93 \mu \mathrm{g} / \mathrm{mL}$ and a clear loss of cell viability was observed (Fig. 4B). Optical microscopy images shown in Fig. 4Ad and 4Bd depict clear morphological changes in both cell types treated with peptide VLES ${ }^{(221-239)}$. At the highest concentration tested, vacuolization was registered in macrophages employing $46 \mu \mathrm{g}$ VLES/mL and with $93 \mu \mathrm{g}$ VLES/mL for microglial cells. Modest cytotoxic effects were observed with both peptides DRV ${ }^{(9-24)}$ (Fig. 4Ab, $\mathrm{Bb})$ and $\mathrm{KLL}^{(45-63)}$ (Fig. 4Ac, Bc). From these series of cell viability experiments in correlation to peptide aggregates shown by TEM and AFM, it becomes clear that VLES $^{(221-239)}$ with the presence of small protofilaments associated to oligomers corresponds to the most toxic form of the peptide. 

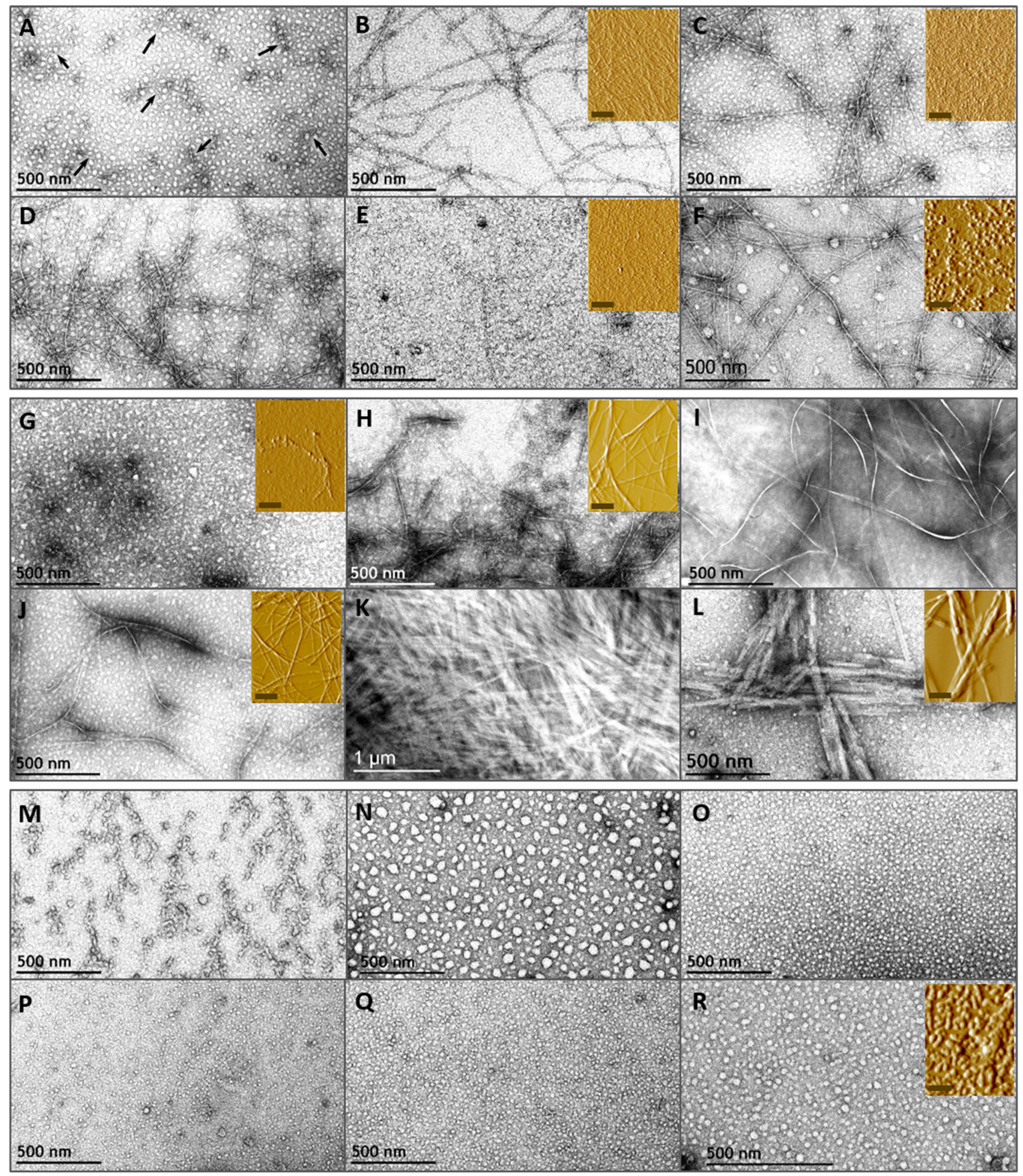

Fig. 3 TEM and AFM micrographs of peptides $\mathrm{DRV}^{(9-24)}$, $\mathrm{KLL}^{(45-63)}$, and VLES ${ }^{(221-239)}$. Evolution of peptide aggregation in water was evaluated by electron and atomic force microscopies on peptides $\operatorname{VLES}^{(221-239)}(A-F), \operatorname{DRV}^{(9-24)}(G-L)$, and $\operatorname{KLL}^{(45-63)}(M-R)$. Incubation times correspond to: $0 \mathrm{~h}(A, G, M), 24 \mathrm{~h}(B, H, N), 48 \mathrm{~h}$
$(C, I, O), 72 \mathrm{~h}(D, J, P), 92 \mathrm{~h}(E, K, Q)$, and 120 days $(F, L, R)$. Arrows $(A)$ show protofibrillar structures. Insets correspond to AFM images of samples used in $\mathrm{CD}$ experiments and the scale correspond to $1 \mu \mathrm{m}$ 
Fig. 4 Cytotoxic effects of apoA-I derived peptides. MTT reductions experiments performed with macrophage (A) and microglial cells $(\mathbf{B})$. Aa-d Optical microscopy images of macrophages treated for $24 \mathrm{~h}$ with peptides previously incubated at $4{ }^{\circ} \mathrm{C}$ in water for 120 days $(46 \mu \mathrm{g} / \mathrm{mL})$. Ba-d) Optical microscopy images of microglial cells treated for $24 \mathrm{~h}$ with peptides previously incubated at $4{ }^{\circ} \mathrm{C}$ in water for 120 days $(93 \mu \mathrm{g} / \mathrm{mL})$. a Control without peptides, b DRV ${ }^{(9-24)}$, c KLL ${ }^{(45-63)}$, and d VLES ${ }^{(221-239)}$
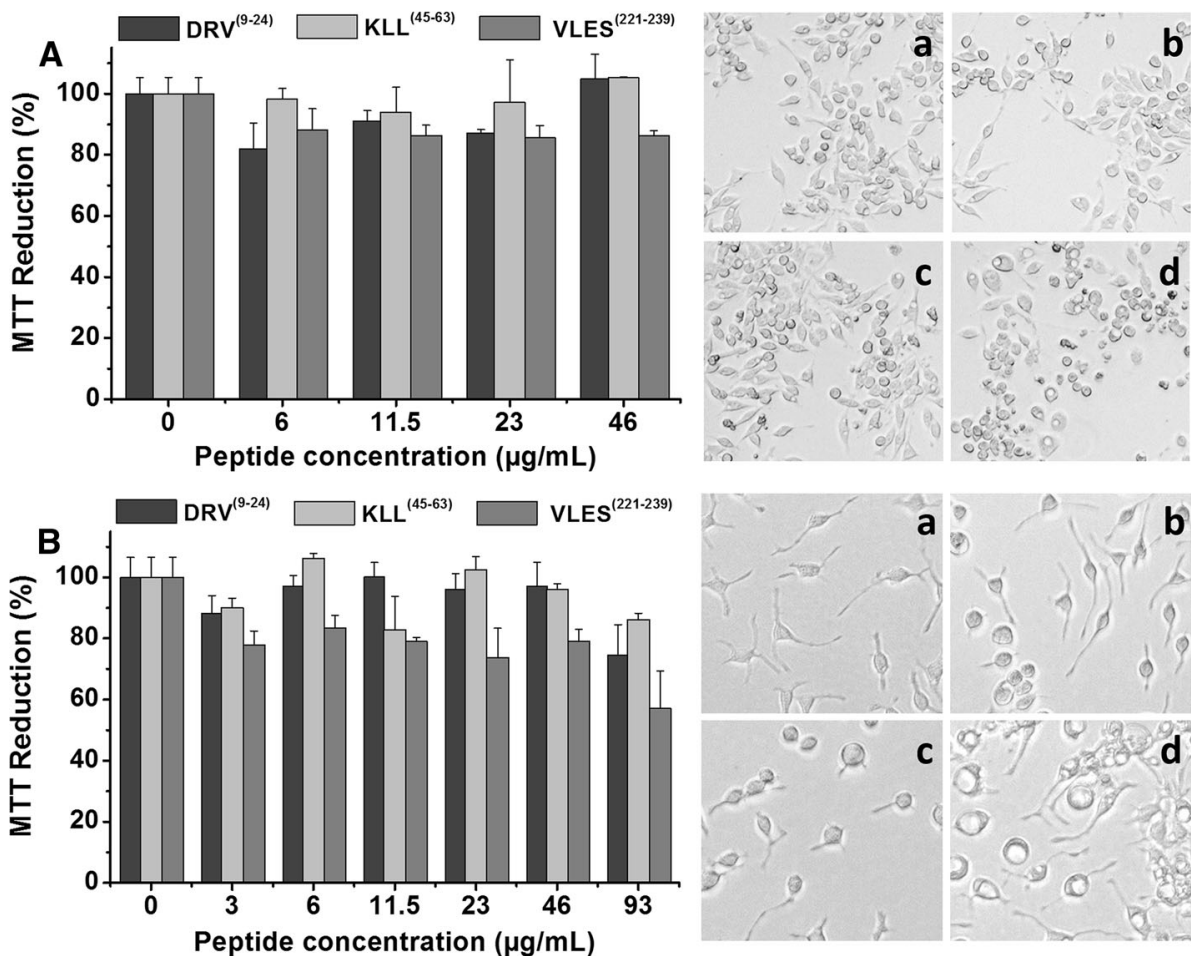

\section{Discussion}

In 1950, Karush [29] proposed that protein-ligand interactions stabilized the best-fitting members within an assembly of structures in equilibrium. Since then, numerous studies have demonstrated that disorder and flexibility in protein structure are important features in the understanding of protein function. In the case of apolipoproteins such as apoA-I, apoC-II, and apoE, it has been found that they correspond to intrinsically disordered proteins. As a consequence of their structural flexibility, the X-ray crystal structure of the C-terminal apoA-I has shown its propensity to destabilization as well as to be able to adopt different conformations when associated to lipids or in a lipid-free state $[30,31]$. The crystal structure of lipid-free apoA-I demonstrated that although it contains a largely helical four-segment bundle [31], when in solution, this segment adopts a molten globule conformation with its $\mathrm{N}$ - terminal domain completely disordered [7].

When apolipoproteins are exposed to air/water and lipid/ water interfaces, evident disorder-to-order conformational transitions take place that might have an important impact upon HDL function [32-34]. In this sense, we have previously shown that conformational transitions observed with a series of apoA-I derived peptides stabilize and improve the enzymatic activity of LCAT [19].

In order to predict which segments of apoA-I could present the greater propensity to develop disorder-to-order transitions, using the PONDR-FIT server, we have studied three segments that bind to lipids and acquire a helical conformation that might contribute to the stabilization of lipid-protein interaction. Within each of the disordered $\mathrm{N}$ and C-terminal domains, small segments of hydrophobic $\beta$ sheet structure are exposed and, therefore, proposed to interact with lipids [7, 20]. Our analysis using the HCA server revealed three highly hydrophobic clusters within the helical structure of apoA-I, being the longest one found at the C-terminal domain. This result supports our previous reports and also suggests that lipid-free apoA-I first binds membrane lipids or surface lipids of lipoproteins through the C-terminal fragment. The presence of nonpolar core residues in the protein may be related with this phenomenon, which does not occur when proteins have an inadequate number of hydrophobic residues.

Peptides studied in this investigation have the particular feature of having a good balance between charge and hydrophobicity that allows them to stay "suspended" as globular structures and due to hydrophobic interactions bound together with the potential to generate fibrillar structures. While peptide DRV ${ }^{(9-24)}$ having a charge of -1 presents the ability to easily generate amyloid-like fibers as previously reported by us [27], peptide $\operatorname{VLES}^{(221-239)}$ with no charge at physiological $\mathrm{pH}$, only form thin protofibrils. Peptide $\mathrm{KLL}^{(45-63)}$ also presenting a net charge of 0 at physiological $\mathrm{pH}$, shows a low efficiency for intermolecular interactions and, therefore, a low propensity for the generation of fibrils.

Peptides and proteins capable of generating amyloid fibers present common hydrophobic structural blocks 
called "steric zippers" [35]. Interestingly, $\mathrm{DRV}^{(9-24)}$ in addition to presenting the highest $\mu \mathrm{H}$, also contains a "steric zipper" with the highest average hydrophobicity value when compared to peptides $\mathrm{KLL}^{(45-63)}$ and VLES $^{(221-239)}$. Although peptide $\mathrm{KLL}^{(45-63)}$ is the most polar of the three peptides tested, it also contains a "steric zipper" showing weaker hydrophobic characteristics than those present in peptides $\operatorname{DRV}^{(9-24)}$ and VLES ${ }^{(221-239)}$. This characteristic indicates the absence of an adequate nucleation center that might self-assemble and, therefore, the difficulty to generate fibrillar structures. CD spectra deconvolution for peptides $\mathrm{DRV}^{(9-24)}$ and $\operatorname{VLES}^{(221-239)}$ suspended in water, showed over time a moderate increase in $\alpha$-helix content despite microscopy evidence of fibril formation (Table 2). CD spectra deconvolution for peptide KLL $^{(45-63)}$ suggests that the formation of $\beta$-sheet structures alone is insufficient to induce protein aggregation and fibril formation. On the other hand, the use of the software Zyggregator predicted that propensity for amyloid-like fibril formation was similar for peptides $\mathrm{DRV}^{(9-24)}$, $\mathrm{KLL}^{(45-63)}$, and VLES ${ }^{(221-239)}$ (Fig. 2b).

We recognize three elemental features in peptides $\mathrm{DRV}^{(9-24)}$ and $\mathrm{VLES}^{(221-239)}$ that lead to protein aggregation. In the first place, peptides present a steric zipper characteristic of amyloidogenic proteins in the form of tandems of hydrophobic and nonpolar amino acids (Table 1). Second, the presence of aromatic amino acids, in particular phenylalanine, is related with self-assembly of amyloid fibrils. Finally, we observed a size uniformity of the steric zipper and adjacent regions, a property related to protein-protein interactions that drive amyloid-like formation. The existence of unstructured segments at the $\mathrm{N}$ and C-terminal domains of apoA-I makes the protein susceptible to enzymatic hydrolysis [36], phenomenon that increases the probability for the generation of highly hydrophobic autoimmune structures that in turn might induce an inflammatory response [33, 37, 38] promoting the generation of nucleation centers important in the formation of amyloid-like fibrils (Fig. 5) [39-42]. In addition, under proteolytic conditions, it has been observed that apoA-I/HDL releases peptides from its terminal domains showing the same properties as when they are in a lipid medium [43, 44]. During our viability assays, peptide VLES $^{(221-239)}$ and to a lesser extent $\mathrm{DRV}^{(9-24)}$, the two peptides that generate fibers, have the ability to promote cytotoxicity. $\operatorname{VLES}^{(221-239)}$ also presents the property to alter the cell membrane as observed by optical microscopy (Fig. 4Bd). Conducting an analysis of peptide sequence motifs capable of interacting with membranes or phospholipidic surfaces [45, 46], it is observed that peptide $\mathrm{DRV}^{(9-24)}$ presents amino acids with a net positive charge (lysine and arginine) and aromatic amino acids. Interestingly, peptide $\mathrm{KLL}^{(45-63)}$ showing a lysine residue at the
$\mathrm{N}$ - terminal, two aromatic amino acids, and several nonpolar residues resembling the phospholipid polar head might promote the formation of "peptide micelles" [47]. It has been established that electrostatic interactions between positive residues located at the protein and the presence of negatively charged phospholipids, are the dominant forces that promote adsorption of the protein onto the membrane surface [48]. On the other hand, nonpolar interactions between hydrophobic segments of the protein and the presence of lipid hydrophobic chains, lead to the insertion of the protein into the membrane interface [45]. In our hands, incubation of cells in a medium containing VLES $^{(221-239)}$ showing an $\boldsymbol{\alpha}$-helical structure when associated to lipid molecules, seems to be the conformation that mostly damage cells [40, 49]. From the images seen with TEM and AFM, it can be concluded that the presence of $\mathrm{VLES}^{(221-239)}$ in the form of small protofilaments and oligomers corresponds to structural forms associated to a high degree of cytotoxicity.

Based on the conformational transitions and cytotoxicity associated to the apoA-I derived peptides used in this work, we suggest that transitions leading to an $\alpha$-helix formation in this protein at the hydrophilic/hydrophobic interface of membranes can be considered a key feature to explain cell toxicity.

Our study puts into perspective the fact that highly hydrophobic segments of apoA-I present the ability to develop secondary structure disorder-to-order transitions depending on the molecules to which it is associated. The association of these highly hydrophobic segments to specific types of lipid molecules could shift the equilibrium toward the consolidation of $\alpha$-helical segments that would apparently warranty the normal function of the protein. In contrast, if these segments follow protein-protein interactions or are kept in highly hydrophilic environments, the possibility for the generation of localized pro-aggregation structures might disrupt the normal function of apoA-I.

The dynamic structure exhibited by apoA-I basically supported by intrinsically disordered exposed segments that undergo disorder-to-order and order-to-disorder conformational transitions might also explain the exchangeability properties shown by this family of apolipoproteins. When the protein is located in a highly hydrophilic media with its lateral segments exposed, these segments mostly show a disordered conformation and the permanence of the protein in plasma maintained. Nevertheless, when these segments start to get associated to lipid, there is a shift toward organized secondary conformational structures mostly $\alpha$-helical structures that in a continuum tend to change the equilibrium, toward the formation and consolidation of lipid loaded particles that eventually give rise to the generation of HDL.

For many years, protein function had resided in the fact that well-ordered structures mostly through rigid 


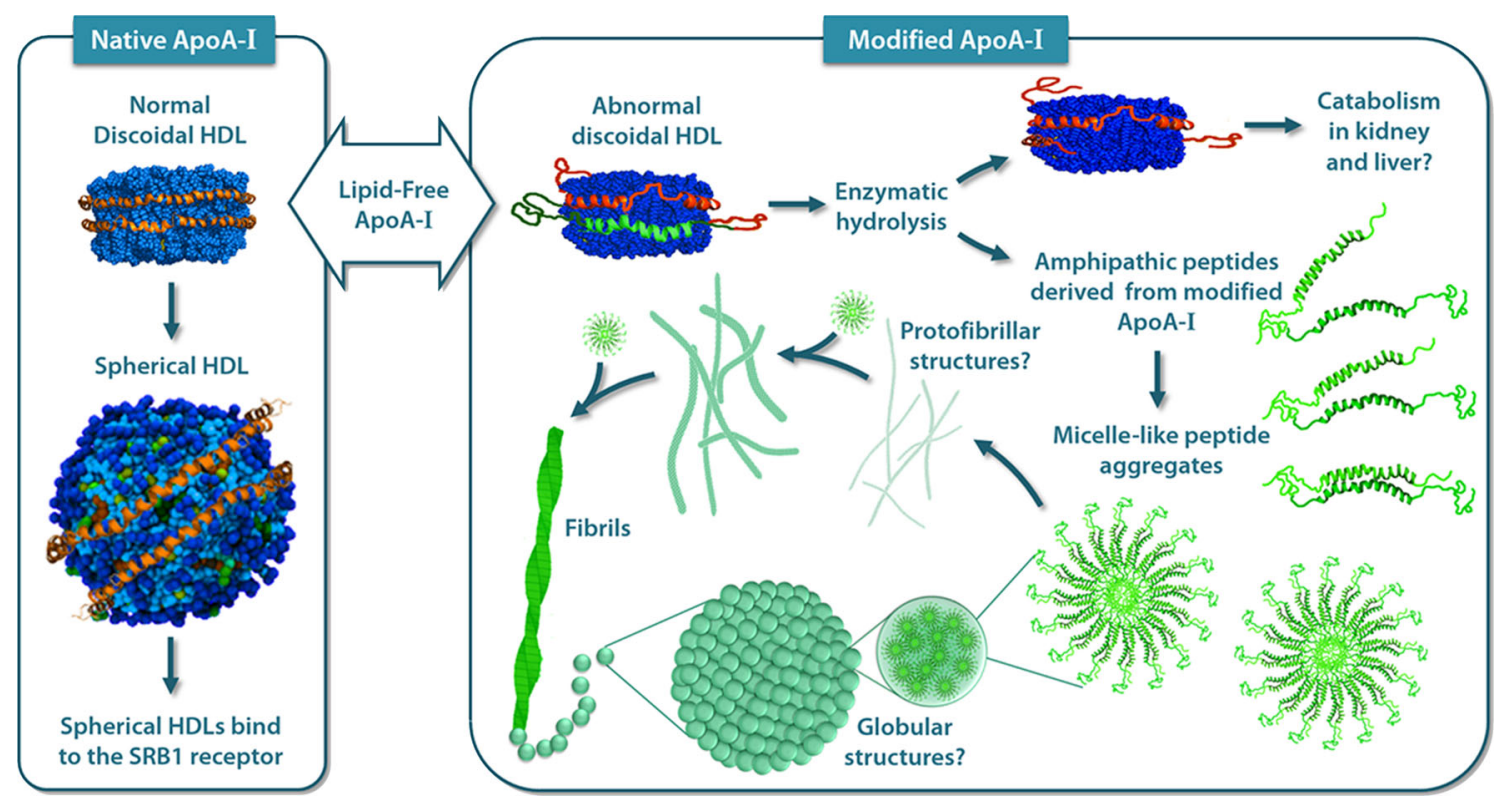

Fig. 5 ApoA-I aggregation properties. Lipid-poor apoA-I interacts with the ABCA1 receptor and produce discoidal structures following a process still under active investigation. Discoidal particles are transformed into spherical HDLs by the action of the LCAT enzyme [39]. Only the spherical forms of HDL can interact with the SRB1 receptor. Modified apoA-I can not interact properly with the ABCA1 receptor forming smaller abnormal discoidal HDLs [40]. A direct consequence of this condition is the exposure of highly unstructured apoA-I segments prone to enzymatic hydrolysis [41]. Peptides released by proteolysis might form amyloidogenic structures that can be organized first as micelle-like peptides that can evolve to form globular or protofibrillar structures depending on their residue composition [42, 47]. Modified from [33] tridimensional blocks were fundamental for understanding the way proteins work. Nevertheless, nowadays this concept has been surpassed when recognition has been made to phylogenetically advanced organisms that develop function through and important number of intrinsically disordered proteins and the concept of structural disorder, as a new form of secondary structure of proteins conceived. In this sense, an important number of diseases that in the past had been difficult to understand, during the present days they start to find an explanation in the anomalous folding of proteins [50]. Without a doubt, we can say that, in the near future many diseases with poorly understood origins not only will find a molecular explanation based on this phenomenon, but also in the way intrinsically disordered regions of proteins are modulated.

Acknowledgments We thank B. Delgado-Coello and R. Paredes for their excellent technical assistance. This work was supported by CONACyT (Grant 180726) and DGAPA-UNAM (Grant RR205711) awarded to J. Mas-Oliva. P. Mendoza-Espinosa, D. Montalvan-Sorrosa (Biomedical Sciences) and V. García-González (Biochemical Sciences) were supported by a fellowship granted by Consejo Nacional de Ciencia y Tecnología (CONACyT) for Ph.D studies at Universidad Nacional Autónoma de México (UNAM).

Open Access This article is distributed under the terms of the Creative Commons Attribution License which permits any use, distribution, and reproduction in any medium, provided the original author(s) and the source are credited.

\section{References}

1. Barter PJ, Rye KA (1996) Molecular mechanisms of reverse cholesterol transport. Curr Opin Lipidol 7:82-87

2. Uversky VN, Gillespie JR, Fink AL (2000) Why are "natively unfolded" proteins unstructured under physiologic conditions? Proteins 41:415-427

3. Dunker AK, Oldfield CJ, Meng J, Romero P, Yang JY, Chen JW, Vacic V, Obradovic Z, Uversky VN (2008) The unfoldomics decade: an update on intrinsically disordered proteins. BMC Genomics 9(Suppl 2):S1. doi:10.1186/1471-2164-9-S2-S1

4. Tompa P (2012) Intrinsically disordered proteins: a 10-year recap. Trends Biochem Sci 37:509-516. doi:10.1016/j.tibs.2012. 08.004

5. Mendoza-Espinosa P, Garcia-Gonzalez V, Moreno A, Castillo R, Mas-Oliva J (2009) Disorder-to-order conformational transitions in protein structure and its relationship to disease. Mol Cell Biochem 330:105-120. doi:10.1007/s11010-009-0105-6

6. Kono M, Okumura Y, Tanaka M, Nguyen D, Dhanasekaran P, Lund-Katz S, Phillips MC, Saito H (2008) Conformational flexibility of the N-terminal domain of apolipoprotein A-I bound to spherical lipid particles. Biochemistry 47:11340-11347. doi:10. 1021/bi801503r

7. Lagerstedt JO, Budamagunta MS, Oda MN, Voss JC (2007) Electron paramagnetic resonance spectroscopy of site-directed spin labels reveals the structural heterogeneity in the $\mathrm{N}$-terminal domain of apoA-I in solution. J Biol Chem 282:9143-9149. doi:10.1074/jbc.M608717200

8. Wang G, Sparrow JT, Cushley RJ (1997) The helix-hinge-helix structural motif in human apolipoprotein A-I determined by NMR spectroscopy. Biochemistry 36:13657-13666. doi:10.1021/ bi971151q 
9. Wang G, Treleaven WD, Cushley RJ (1996) Conformation of human serum apolipoprotein A-I(166-185) in the presence of sodium dodecyl sulfate or dodecylphosphocholine by $1 \mathrm{H}-\mathrm{NMR}$ and CD: evidence for specific peptide-SDS interactions. Biochim Biophys Acta 1301:174-184

10. Okon M, Frank PG, Marcel YL, Cushley RJ (2002) Heteronuclear NMR studies of human serum apolipoprotein A-I. Part I: secondary structure in lipid-mimetic solution. FEBS Lett 517:139-143

11. Okon M, Frank PG, Marcel YL, Cushley RJ (2001) Secondary structure of human apolipoprotein A-I(1-186) in lipid-mimetic solution. FEBS Lett 487:390-396

12. Wu Z, Wagner MA, Zheng L, Parks JS, Shy JM 3rd, Smith JD, Gogonea V, Hazen SL (2007) The refined structure of nascent HDL reveals a key functional domain for particle maturation and dysfunction. Nat Struct Mol Biol 14:861-868. doi:10.1038/ nsmb1284

13. Gogonea V, Gerstenecker GS, Wu Z, Lee X, Topbas C, Wagner MA, Tallant TC, Smith JD, Callow P, Pipich V, Malet H, Schoehn G, DiDonato JA, Hazen SL (2013) The low-resolution structure of nHDL reconstituted with DMPC with and without cholesterol reveals a mechanism for particle expansion. J Lipid Res 54(4):966-983. doi:10.1194/jlr.M032763

14. Gogonea V, Wu Z, Lee X, Pipich V, Li XM, Ioffe AI, Didonato JA, Hazen SL (2010) Congruency between biophysical data from multiple platforms and molecular dynamics simulation of the double-super helix model of nascent high-density lipoprotein. Biochemistry 49:7323-7343. doi:10.1021/bi100588a

15. Wu Z, Gogonea V, Lee X, Wagner MA, Li XM, Huang Y, Undurti A, May RP, Haertlein M, Moulin M, Gutsche I, Zaccai G, Didonato JA, Hazen SL (2009) Double superhelix model of high density lipoprotein. J Biol Chem 284(52):36605-36619. doi:10.1074/jbc.M109.039537

16. Fang Y, Gursky O, Atkinson D (2003) Lipid-binding studies of human apolipoprotein A-I and its terminally truncated mutants. Biochemistry 42:13260-13268. doi:10.1021/bi0354031

17. Huang W, Sasaki J, Matsunaga A, Han H, Li W, Koga T, Kugi M, Ando S, Arakawa K (2000) A single amino acid deletion in the carboxy terminal of apolipoprotein A-I impairs lipid binding and cellular interaction. Arterioscler Thromb Vasc Biol 20:210-216

18. Allan CM, Fidge NH, Kanellos J (1992) Antibodies to the carboxyl terminus of human apolipoprotein A-I. The putative cellular binding domain of high density lipoprotein 3 and carboxylterminal structural homology between apolipoproteins A-I and A-II. J Biol Chem 267(19):13257-13261

19. Aguilar-Espinosa SL, Mendoza-Espinosa P, Delgado-Coello B, Mas-Oliva J (2013) Lecithin cholesterol acyltransferase (LCAT) activity in the presence of Apo-AI-derived exposed to disorderto-order conformational transitions. Biochem Biophys Res Commun 441:469-475

20. Oda MN, Forte TM, Ryan RO, Voss JC (2003) The C-terminal domain of apolipoprotein A-I contains a lipid-sensitive conformational trigger. Nat Struct Biol 10:455-460. doi:10.1038/ nsb931

21. Xue B, Dunbrack RL, Williams RW, Dunker AK, Uversky VN (2010) PONDR-FIT: a meta-predictor of intrinsically disordered amino acids. Biochim Biophys Acta 1804:996-1010. doi:10. 1016/j.bbapap.2010.01.011

22. Callebaut I, Labesse G, Durand P, Poupon A, Canard L, Chomilier J, Henrissat B, Mornon JP (1997) Deciphering protein sequence information through hydrophobic cluster analysis (HCA): current status and perspectives. Cell Mol Life Sci 53:621-645

23. Tartaglia GG, Pawar AP, Campioni S, Dobson CM, Chiti F, Vendruscolo M (2008) Prediction of aggregation-prone regions in structured proteins. J Mol Biol 380:425-436. doi:10.1016/j.jmb. 2008.05.013

24. DuBay KF, Pawar AP, Chiti F, Zurdo J, Dobson CM, Vendruscolo M (2004) Prediction of the absolute aggregation rates of amyloidogenic polypeptide chains. J Mol Biol 341:1317-1326. doi:10.1016/j.jmb.2004.06.043

25. Bohm G, Muhr R, Jaenicke R (1992) Quantitative analysis of protein far UV circular dichroism spectra by neural networks. Protein Eng 5:191-195

26. Manzano-Leon N, Delgado-Coello B, Guaderrama-Diaz M, MasOliva J (2006) Beta-adaptin: key molecule for microglial scavenger receptor function under oxidative stress. Biochem Biophys Res Commun 351:588-594. doi:10.1016/j.bbrc.2006.10.077

27. Garcia-Gonzalez V, Mas-Oliva J (2011) Amyloidogenic properties of a D/N mutated 12 amino acid fragment of the C-terminal domain of the cholesteryl-ester transfer protein (CETP). Int J Mol Sci 12:2019-2035. doi:10.3390/ijms12032019

28. Abe K, Saito H (1999) Both oxidative stress-dependent and independent effects of amyloid beta protein are detected by 3-(4,5-dimethylthiazol-2-yl)-2, 5-diphenyltetrazolium bromide (MTT) reduction assay. Brain Res 830:146-154

29. Karush F (1950) Heterogeneity of the binding sites of bovine serum albumin. J Am Chem Soc 72:2705-2713. doi:10.1021/ $\mathrm{Ja} 01162 \mathrm{a} 099$

30. Borhani DW, Rogers DP, Engler JA, Brouillette CG (1997) Crystal structure of truncated human apolipoprotein A-I suggests a lipid-bound conformation. Proc Natl Acad Sci U S A 94:12291-12296

31. Mei X, Atkinson D (2011) Crystal structure of C-terminal truncated apolipoprotein A-I reveals the assembly of high density lipoprotein (HDL) by dimerization. J Biol Chem 286(44):3857038582. doi:10.1074/jbc.M111.260422

32. Xicohtencatl-Cortes J, Mas-Oliva J, Castillo R (2004) Phase transitions of phospholipid monolayers penetrated by apolipoproteins. J Phys Chem B 108:7307-7315

33. Campos-Terán J, Mendoza-Espinosa P, Castillo R, Mas-Oliva J (2012) conformational and disorder to order transitions in proteins: structure/function correlation in apolipoproteins. In: Cai W, Hong $\mathrm{H}$ (eds) Protein-protein interactions-computational and experimental tools. Intech, Rijeka, pp 331-358. doi:10.5772/ 37217

34. Mendoza-Espinosa P, Moreno A, Castillo R, Mas-Oliva J (2008) Lipid dependant disorder-to-order conformational transitions in apolipoprotein CI derived peptides. Biochem Biophys Res Commun 365:8-15. doi:10.1016/j.bbrc.2007.10.112

35. Nelson R, Sawaya MR, Balbirnie M, Madsen AO, Riekel C, Grothe R, Eisenberg D (2005) Structure of the cross-beta spine of amyloid-like fibrils. Nature 435:773-778. doi:10.1038/nature 03680

36. Gursky O, Mei X, Atkinson D (2012) The crystal structure of the C-terminal truncated apolipoprotein A-I sheds new light on amyloid formation by the N-terminal fragment. Biochemistry 51(1):10-18. doi:10.1021/bi2017014

37. Lee M, Kovanen PT, Tedeschi G, Oungre E, Franceschini G, Calabresi L (2003) Apolipoprotein composition and particle size affect HDL degradation by chymase: effect on cellular cholesterol efflux. J Lipid Res 44:539-546. doi:10.1194/jlr.M200420JLR200

38. Seong SY, Matzinger P (2004) Hydrophobicity: an ancient damage-associated molecular pattern that initiates innate immune responses. Nat Rev Immunol 4(6):469-478. doi:10.1038/nri1372

39. Toth PP (2003) Reverse cholesterol transport: high-density lipoprotein's magnificent mile. Curr Atheroscler Rep 5:386-393

40. Genschel J, Haas R, Pröpsting MJ, Schmidt HHJ (1998) Hypothesis: apolipoprotein A-I induced amyloidosis. FEBS Lett 430:145-149. doi:10.1016/S0014-5793(98)00668-1 
41. Ramella NA, Rimoldi OJ, Prieto ED, Schinella GR, Sanchez SA, Jaureguiberry MS, Vela ME, Ferreira ST, Tricerri MA (2011) Human apolipoprotein A-I-derived amyloid: its association with atherosclerosis. PLoS One 6:e22532. doi:10.1371/journal.pone. 0022532

42. Abedini A, Raleigh DP (2009) A critical assessment of the role of helical intermediates in amyloid formation by natively unfolded proteins and polypeptides. Protein Eng Des Sel 22:453-459. doi:10.1093/protein/gzp036

43. Gillotte KL, Davidson WS, Lund-Katz S, Rothblat GH, Phillips MC (1996) Apolipoprotein A-I structural modification and the functionality of reconstituted high density lipoprotein particles in cellular cholesterol efflux. J Biol Chem 271(39):23792-23798

44. Mishra VK, Palgunachari MN, Datta G, Phillips MC, Lund-Katz S, Adeyeye SO, Segrest JP, Anantharamaiah GM (1998) Studies of synthetic peptides of human apolipoprotein A-I containing tandem amphipathic alpha-helixes. Biochemistry 37(28):1031310324. doi:10.1021/bi980042o

45. McGaughey GB, Gagne M, Rappe AK (1998) pi-Stacking interactions. Alive and well in proteins. J Biol Chem 273(25):15458-15463
46. Palgunachari MN, Mishra VK, Lund-Katz S, Phillips MC, Adeyeye SO, Alluri S, Anantharamaiah GM, Segrest JP (1996) Only the two end helixes of eight tandem amphipathic helical domains of human apo A-I have significant lipid affinity. Implications for HDL assembly. Arterioscler Thromb Vasc Biol 16(2):328-338

47. Kumaraswamy P, Sethuraman S, Krishnan UM (2013) Hierarchical self-assembly of Tjernberg peptide at nanoscale. Soft Matter 9:2684-2694. doi:10.1039/C2sm27143e

48. Splith K, Neundorf I (2011) Antimicrobial peptides with cellpenetrating peptide properties and vice versa. Eur Biophys $\mathbf{J}$ 40(4):387-397. doi:10.1007/s00249-011-0682-7

49. Quist A, Doudevski I, Lin H, Azimova R, Ng D, Frangione B, Kagan B, Ghiso J, Lal R (2005) Amyloid ion channels: a common structural link for protein-misfolding disease. Proc Natl Acad Sci U S A 102(30):10427-10432. doi:10.1073/pnas.0502066102

50. García-González V, Mas-Oliva J (2012) El Concepto de Enfermedad Asociado a la Conformación de Proteínas, 1st edn. Universidad Nacional Autónoma de México and El Manual Moderno, México. ISBN 978-607-02-3363-0 